\title{
Self-medication of abortion pills and its complications: an observational study
}

\author{
Kavina S. Munshi, Rajal V. Thaker*, Jagruti M. Shah, Bhavna N. Mewada
}

Department of Obstetrics and Gynecology, Smt NHL Municipal Medical College, SCL Hospital, Ahmedabad, India

Received: 26 October 2017

Accepted: 25 November 2017

\author{
*Correspondence: \\ Dr. Rajal V. Thaker, \\ E-mail: drrajalthaker@gmail.com
}

Copyright: ( $)$ the author(s), publisher and licensee Medip Academy. This is an open-access article distributed under the terms of the Creative Commons Attribution Non-Commercial License, which permits unrestricted non-commercial use, distribution, and reproduction in any medium, provided the original work is properly cited.

\begin{abstract}
Background: Medical termination of pregnancy has been legalized in India since 1971. Medical abortion pill is well effective in early weeks of pregnancy. It is safe only when it is used under medical supervision. This study was carried out to analyse the complications following self-medication of abortion pills and to suggest measures to prevent such practice.

Methods: This was a retrospective observational study conducted at our hospital from March 2017 to July 2017.

Results: In present study $30(75 \%)$ patients were in age group of 20-30 years. Illiterate patients were 22 (55\%). Half of the patients, $20(50 \%)$ were having three or more than three children. Majority of women $30(75 \%)$ had consumed the abortion pills 1-10 days before coming to the hospital and $14(35 \%)$ of patients had come with complain of excessive bleeding per vagina. Incomplete abortion was present in $32(80 \%)$ of patients. Instrumental evacuation was required in $28(87.5 \%)$ patients. Laparotomy for ruptured ectopic and rupture uterus was performed in 1 (2.5\%) of each patient. $6(15 \%)$ patients were severely anaemic. Transfusion of blood was required in $9(22.5 \%)$ of patients.

Conclusions: Medical abortion is effective and safe when carried out under medical supervision. Unsupervised use of medical abortion pills was associated with many complications like incomplete abortion, rupture ectopic and ruptured uterus. So, over the counter sale of medical abortion pill should be restricted.
\end{abstract}

Keywords: Abortion pills, Medical abortion, Self-medication

\section{INTRODUCTION}

Medical abortion is a safe method of termination of pregnancy when performed as per guidelines with success rate of 95 to $99 \% .{ }^{1}$ Commonly used drugs for medical methods of abortion are a combination of mifepristone and misoprostol. Drug Controller General of India approved the use of Mifepristone (in April 2002) and Misoprostol (in December 2006) for termination of pregnancy up to 49 days gestation period. In December 2008, Mifepristone + Misoprostol (1 tab of mifepristone $200 \mathrm{mg}$ and $4 \mathrm{tab}$ of misoprostol $200 \mathrm{mcg}$ each) Combipack was approved by the Central Drugs Standard Control Organization, Directorate General of Health
Services for the medical termination of intrauterine pregnancy (MTP) for up to 63 days gestation. ${ }^{2}$ Federation of Obstetrics and Gynecological Societies of India (FOGSI) recommends close monitoring of distribution of drugs that are used for medical abortion and that the medical profession and pharmaceutical industry should exercise due diligence in the promotion and usage of drugs that are used for medical abortion. ${ }^{3}$ As per the MTP law of India, abortion pills can only be prescribed by registered medical practitioner. ${ }^{4}$ But self-administration of abortion pills is rampant throughout the country due to over the counter availability of these drugs and complications are not uncommon due to this practice. The society perceives unsupervised medical abortion as a 
very safe method of termination and women use this as a method of spacing. Hence, this study was carried out to analyse the complications following self-medication of abortion pills and to suggest measures to prevent such practice.

\section{METHODS}

This was a retrospective observational study conducted at our hospital from March 2017 to July 2017 after due permission from authority. Data was collected from 40 patients who had come after self-medication (purchased the drug by self or by family members without medical guidance or supervision) for medical method of termination of pregnancy. After taking detailed history and clinical examination, all patients were admitted and treated after routine investigations and sonography. Data was collected from all patients regarding their age, marital status, education, obstetric history, duration of intake of abortion pills and visit to hospital, chief complain and sign-symptoms on arrival at hospital, investigations and ultrasonography at time of admission, treatment given, management of complications, need for blood/blood product transfusion and duration of hospital stay. Analysis of data was done with help of appropriate statistical tool.

\section{RESULTS}

Despite MTP law, patient/her relative had procured the MTP pills without prescription and had consumed without medical supervision and appropriate protocol. Total of 40 patients were studied. Data obtained was as follows.

Table 1: Demographic data $(\mathrm{N}=40)$.

\begin{tabular}{|lll|}
\hline Age (years) & No. & $\%$ \\
\hline$<19$ & 3 & 7.5 \\
\hline $20-25$ & 13 & 32.5 \\
\hline $26-30$ & 17 & 42.5 \\
\hline $31-35$ & 7 & 17.5 \\
\hline Education & & \\
\hline Nil & 22 & 55 \\
\hline Primary & 9 & 22.5 \\
\hline Secondary & 4 & 10 \\
\hline Higher secondary & 3 & 7.5 \\
\hline College & 2 & 5 \\
\hline No. of children & & \\
\hline 1 & 4 & 10 \\
\hline 2 & 16 & 40 \\
\hline 3 or more & 20 & 50 \\
\hline
\end{tabular}

As shown in Table 1, majority of patients 17 (42.5\%) were in age group of 26-30 years. In the age group of 2030 years, there were $30(75 \%)$ patients. Uneducated patients were $22(55 \%)$, whereas primary education was present in $9(22.5 \%)$ patients. Half of the patients, 20 $(50 \%)$ were having three or more than three children.
History of previous one or more caesarean delivery was present in $10(25 \%)$ of patients. All patients were married.

As shown in Table 2, as per history received from patients, $25(62.5 \%)$ had consumed the tablets upto 9 weeks of pregnancy, $13(32.5 \%)$ had consumed between 9-12 weeks and $2(5 \%)$ had consumed beyond 12 weeks of gestation.

Table 2: Gestation weeks $(\mathrm{N}=40)$.

\begin{tabular}{|lll|}
\hline Gestation weeks & No. & $\%$ \\
\hline Up to 9 weeks & 25 & 62.5 \\
\hline $9-12$ weeks & 13 & 32.5 \\
\hline$>12$ weeks & 02 & 05 \\
\hline
\end{tabular}

As shown in Table 3, majority of women, 30 (75\%) had consumed the abortion pills 1-10 days before coming to the hospital. There were $8(20 \%)$ of patients who had consumed abortion pills before three weeks or more.

Table 3: Duration of consumption of abortion pills before admission to hospital $(\mathrm{N}=40)$.

\begin{tabular}{|lll|}
\hline $\begin{array}{l}\text { No. of days since consumption } \\
\text { of pills to hospital visit }\end{array}$ & No. & $\%$ \\
\hline $1-10$ days & 30 & $75 \%$ \\
\hline $11-20$ days & 2 & $5 \%$ \\
\hline $21-30$ days & 4 & $10 \%$ \\
\hline$>1$ month & 4 & $10 \%$ \\
\hline
\end{tabular}

As shown in Table 4, 14 (35\%) of patients had come with complain of excessive bleeding per vagina and 13 $(32.5 \%)$ of patients had complain of bleeding per vagina associated with abdominal pain. Irregular bleeding per vaginum was present in $10(25 \%)$. Giddiness and fainting was chief complain in $2(5 \%)$ of patients and in $1(2.5 \%)$ of patients, product of conception was not expelled.

Table 4: Complaints on arrival at hospital $(N=40)$.

\begin{tabular}{|lll|}
\hline Complaints on arrival & No. & $\%$ \\
\hline Excessive bleeding per vagina & 14 & 35 \\
\hline Bleeding with abdominal pain & 13 & 32.5 \\
\hline Irregular bleeding per Vagina & 10 & 25 \\
\hline Giddiness and fainting & 02 & 5 \\
\hline Product of conception not expelled & 01 & 2.5 \\
\hline
\end{tabular}

As shown in Table 5, diagnosis of incomplete abortion was made in $32(80 \%)$ of patients. After per vaginal insertion of tablet Misoprostol, complete abortion occurred in $4(12.5 \%)$. Instrumental evacuation was required in $28(87.5 \%)$ patients. Complete abortion had occurred in $5(12.5 \%)$ of patients, who were given antibiotics and analgesics. In $1(2.5 \%)$ patient, there was live intra uterine pregnancy and as patient was willing for its termination, dilatation and evacuation was performed after intravaginal insertion of tablet misoprostol. 
Laparotomy for ruptured ectopic pregnancy was performed in $1(2.5 \%)$ patient and salpingectomy was done. A patient who had history of previous two caesarean section came in shock due to rupture uterus for which hysterectomy was performed. In the present study, $6(15 \%)$ patients were severally anaemic and $16(40 \%)$ were having moderate anaemia. Transfusion of blood was required in $9(22.5 \%)$ of patients.

Table 5: Diagnosis and management $(\mathrm{N}=40)$.

\begin{tabular}{|c|c|c|c|}
\hline Diagnosis & No. & $\%$ & Management \\
\hline Incomplete abortion & 32 & 80 & $\begin{array}{l}\text { After intravaginal } \\
\text { insertion of tablet } \\
\text { Misoprostol } \\
4 \text { - complete abortion } \\
\text { 28-instrumental } \\
\text { evacuation }\end{array}$ \\
\hline Complete abortion & 05 & 12.5 & Antibiotics \\
\hline $\begin{array}{l}\text { Live intrauterine } \\
\text { pregnancy }\end{array}$ & 01 & 2.5 & $\begin{array}{l}\text { Tab Misoprostol } \\
\text { followed by } \\
\text { instrumental } \\
\text { evacuation }\end{array}$ \\
\hline $\begin{array}{l}\text { Rupture ectopic } \\
\text { pregnancy }\end{array}$ & 01 & 2.5 & Laparotomy \\
\hline Rupture uterus & 01 & 2.5 & Hysterectomy \\
\hline
\end{tabular}

\section{DISCUSSION}

In India MTP Act was passed in 1971 to prevent unsafe and illegal abortion with the aim of reducing the number of maternal morbidity and mortality due to unsafe abortion. ${ }^{4}$ Any procedure which is performed outside the bounds of law tends to be unsafe. Due to easy availability of MTP pills over the counter, 40 patients came to our hospital with self-medication of MTP pills in spite of clear guidelines that these pills have to be taken only under medical supervision and can be prescribed only by a person authorized under the MTP Act.

Three patients $(7.5 \%)$ were less than 19 years of age who already had one child and had not used any method of contraception for spacing. So, these patients took this pill to get rid of unwanted pregnancy. In a study by Sarojini et al $3.8 \%$ patients were less than 19 years of age. ${ }^{5}$ In present study, majority of patients were in age group of 26-30 years which is comparable to the study by Sarojini et al where majority of women, $37.5 \%$ were in same age group. In present study, $50 \%$ of patients were multigravida. In a study by Sarojini et al, majority of patients were multigravida. ${ }^{5}$

As per the guidelines for medical abortion in India, medical abortion is offered only to those patients, who are ready for minimum three follow-up visits, can understand the instructions, ready for surgical procedure if failure or excessive bleeding occurs, good family support and easy access to appropriate healthcare facility. ${ }^{6}$
Counselling, careful history taking, and clinical examination is must. Pregnancy confirmation for its gestational age and location is also very important and where available, urine test for pregnancy and an USG examination for confirmation of intra uterine pregnancy along with the exact gestational age should be done in all cases. Laboratory tests such as hemoglobin level, blood group and rhesus (Rh) typing, and screening for hepatitis, human immunodeficiency virus (HIV), and sexually transmissible Infections (STIs), may be offered on the basis of individual risk factors or available resources. Patient selection is very important and contraindications for use of medical abortion must be ruled out. After taking formal consent, the recommended protocol is oral $200 \mathrm{mg}$ of Mifepristone on first day. After 36-48 hours 800 micrograms of vaginal Misoprostol or 400 micrograms of oral Misoprostol is given. The tablets are to be taken under medical supervision. The patient is asked to report immediately if excessive bleeding, pain, fainting or any problem occurs. Average blood loss in medical abortion may be more than that in surgical abortion.

On third visit at $15^{\text {th }}$ day, clinical history and pelvic examination should be done to ensure that there are no complications and abortion is complete. USG is required if history and examination do not confirm expulsion of products of conception. If woman is still having irregular bleeding, surgical curettage may be required.

Majority of patients, $25(62.5 \%)$ had consumed the tablets up to 9 weeks of pregnancy which is prescribed limit as per recommendation. But 13 (32.5\%) had consumed between 9-12 weeks and 2 (5\%) had consumed beyond 12 weeks of gestation. Patient needs to be counselled about the fact that this method is possible for intrauterine pregnancies of less than 9 weeks. It does not terminate ectopic pregnancy. ${ }^{2}$ In a study by Sarojini et al, $64.4 \%$ of patients had consumed the pills beyond the recommended period of gestation. ${ }^{5}$

In $14(35 \%)$ of patients' chief complain on admission was excessive bleeding per vagina and $13(32.5 \%)$ of patients had complain of bleeding per vagina associated with abdominal pain. In a study by Sarojini et al, $69.3 \%$ patients reported with bleeding per vaginum and $11.5 \%$ had reported with pain in abdomen..$^{5}$ In the present study, irregular bleeding per vaginum was present in $10(25 \%)$ and giddiness with fainting was chief complain in $2(5 \%)$ of patients. In a study by Sarojini et al, $2.9 \%$ of patients were admitted with shock.

Diagnosis of incomplete abortion was made in $32(80 \%)$ of patients. Out of these, instrumental evacuation was required in $28(87.5 \%)$ patients. In a study by Sarojini et al, instrumental evacuation was required in $90.4 \%$. When drug is given under medical supervision, 1-2\% women may need surgical evacuation for heavy bleeding and 2$3 \%$ may need surgical evacuation due to incomplete abortion. $^{5,2}$ 
In $1(2.5 \%)$ patient, there was live intra uterine pregnancy and as patient was willing for its termination, dilatation and evacuation was performed after intravaginal insertion of tablet misoprostol. In a study by Sarojini et al, live intrauterine gestation was present in $1.9 \%$ of patients. As per guidelines, $1 \%$ may fail to abort. In such a case since there is a possibility of congenital malformation in the fetus a surgical MTP by suction evacuation is advisable. ${ }^{2,5}$

Laparotomy for ruptured ectopic pregnancy was performed in $1(2.5 \%)$ patient and salpingectomy was done. In a study by Sarojini et al, ruptured ectopic pregnancy was present in $1.9 \% .^{5}$

One patient who had history of previous two cesarean section came in shock due to rupture uterus for which hysterectomy was performed. This patient had consumed the pills in second trimester. The chance of scar rupture in post caesarean pregnancy following first trimester medical abortion is non-existent but the risk of rupture is $0.28 \%$ in II trimester abortions. ${ }^{7}$ In a study by Sarojini et al, rupture uterus was present in $1.9 \%$ of patients. ${ }^{5}$

In the present study, $6(15 \%)$ patients were severely anaemic and $16(40 \%)$ were having moderate anaemia. Transfusion of blood was required in 9 (22.5\%) of patients. More than two units of blood were required in 4 patients where as in 5 patients, two units of blood were given. In a study by Sarojini et al, blood transfusions were required in $75 \%$ of patients, out of these, $52 \%$ were given one unit and $23 \%$ were given more than one unit. ${ }^{5}$ Complications like excessive bleeding per vaginum, rupture ectopic and rupture uterus can be life threatening in already anaemic patient. When drugs are given under medical suoervision, only 1-2 per thousand may need blood transfusion due to heavy bleeding. ${ }^{2}$ In a study by Deshpande et al, no woman required blood transfusion when drugs were given under medical supervision. ${ }^{8}$

Findings from a population-based study of using online telemedicine suggest that

- Women's self-reports of outcomes and complications of medical abortion and provides the best evidence to date that self-sourced medical abortion through online telemedicine is highly effective and that rates of adverse events are low. $94.7 \%$ of women were able to successfully terminate their pregnancy without surgical intervention. $0.7 \%$ women received a blood transfusion and $2.6 \%$ women received antibiotics. No deaths related to the intervention were reported

- Reported rates of successful medical abortion are comparable with protocols in clinics, and women report successfully self-screening for potentially serious complications and seeking medical assistance when necessary

- For the millions of women worldwide living in areas where access to abortion is restricted, the findings show the vital role-played by self-sourced medical abortion in providing an option with high effectiveness rates and few reported adverse outcomes. These findings suggest that self-sourced medical abortion using online telemedicine "can be highly effective"

Present study highlights complications following selfmedication of abortion pills that were taken without proper screening, monitoring and protocol. In present study, illiterate patients were $55 \%$ and only $5 \%$ of patient had studied up to college level. Level of education has great impact on women's health for health seeking behavior. Intense awareness generation through a mass media approach, stressing on female literacy, improving the overall socioeconomic conditions, along with counseling on the benefits of timely and appropriate healthcare-seeking behaviors, both in preventive and curative aspects, may lead to the desired health outcomes and favorable health indicators. ${ }^{10}$

Health education and awareness regarding lifethreatening consequences after self-medication of abortion pills can help to prevent maternal morbidity and mortality.

\section{CONCLUSION}

Medical abortion is effective and safe when carried out under medical supervision. Unsupervised use of medical abortion pills was associated with many complications like higher chances of incomplete abortion, hemorrhage, ectopic pregnancy and rupture uterus necessitating blood transfusion. So, over the counter sale of medical abortion pill should be restricted. Health education and awareness regarding life-threatening consequences after selfmedication of abortion pills can help to prevent maternal morbidity and mortality.

\section{Funding: No funding sources}

Conflict of interest: None declared

Ethical approval: The study was approved by the Institutional Ethics Committee

\section{REFERENCES}

1. Use of RU-486 with Misoprostol for early abortions in India. Guidelines for Medical Officers, WHOCCR in Human Reproduction. All India Institute of Medical Sciences, Ministry of Health and Family Welfare, Government of India and Indian Council of Medical Research. 2003

2. Handbook on medical methods of abortion. Available http://www.health.mp.gov.in/mtp/MMA-

Reference\%20Manual.pdf

3. The Federation of Obstetric and Gynaecological Societies of India. Available at http://www.fogsi.org/index.php?option=com_content $\&$ view $=$ article $\&$ id=97 $\&$ Itemid $=16$ 
4. Government of India. The medical termination of pregnancy rules (amendment). 2003. Ministry of Health and Family Welfare. Department of Family Welfare: Notifi cation, New Delhi, the $13^{\text {th }}$ June 2003. Available at http://mohfw.nic.in/index1.php?sublinkid=3618\&lev el=4\&lid=26020\&lang=1. Accessed $11^{\text {th }}$ June 2015.

5. Sarojini TR, Ashakiran BT, Bhanu, Radhika. Overthe-counter MTP Pills and Its Impact on Women's Health. J Obstet Gynecol India. 2017;67(1):37-41.

6. Refresher Course of Medical Abortion Services. Available at www.ipas.org/ /media/Files/Ipas\%20Publications/R EFMAINDE09.ashx.

7. Goyal V. Uterine rupture in second trimester pregnancy termination in women with a prior caesarean delivery: a systematic review. Obstet Gynecol. 2009;113:1117-23.

8. Deshpande S, Yelikar K, Deshmukh A Kanade K. Comparative study of medical abortion by
Mifepristone with vaginal Misoprostol in women $<49$ days versus 50-63 days of amenorrhoea. J Obstet Gynecol India. 2010;60(5):403-7.

9. Aiken ARA, Digol I, Trussell J, Gomperts R. Selfreported outcomes and adverse events after medical abortion through online telemedicine: population based study in the Republic of Ireland and Northern Ireland. BMJ 2017;357.

10. Ghosh N, Chakrabarti I, Chakraborty M, Biswas R. Factors affecting the healthcare-seeking behavior of mothers regarding their children in a rural community of Darjeeling district, West Bengal. Int $\mathbf{J}$ Med Public Health. 2013;3:12-6.

Cite this article as: Munshi KS, Thaker RV, Shah JM, Mewada BN. Self-medication of abortion pills and its complications: an observational study. Int J Reprod Contracept Obstet Gynecol 2018;7:205-9. 